\title{
Laser-based manufacturing concepts for efficient production of tailor welded sheet metals
}

\author{
Marius Spöttl $\cdot$ Hardy Mohrbacher
}

Received: 9 July 2014 / Accepted: 24 July 2014/Published online: 2 September 2014

(C) Shanghai University and Springer-Verlag Berlin Heidelberg 2014

\begin{abstract}
Laser welding is an established manufacturing technology for a large variety of automotive applications due to its attractive properties such as low heat input, high precision and fast welding speed. Especially when welding high strength steels, which are dominantly used in today's car body construction, the low heat input by laser welding bears significant advantages with regard to the properties of the weld seam. The exploitation of the full application potential of laser welding in mass production requires an appropriate manufacturing concept and corresponding auxiliary technologies. The present paper demonstrates the integration of laser welding into the surrounding manufacturing concepts by a modular setup with different levels of automation. This approach offers flexible solutions for individual needs thereby optimizing investment cost, labor cost and productivity. Recently available laser sources enable exceptionally high welding speed on thin gauged sheet metals but require efficient material handling concepts to utilize the full speed potential. Industrial concepts are presented offering efficient material handling and high process robustness for mass production welding.
\end{abstract}

Keywords Laser welding - Tailored blanks - Tailored coils · Material handling · Process robustness - Laser beam splitting · Turbo-welding · Weld edge conditioning

M. Spöttl

WISCO Lasertechnik GmbH, Ravensburg, Germany

H. Mohrbacher ( $\square)$

NiobelCon bvba, Schilde, Belgium

e-mail: hm@niobelcon.net

\section{Introduction}

Laser welded steel blanks have made a remarkable evolution from rather infrequent applications at the end of the 1980 's to an indispensable semi-product in today's automotive body design. Within a decade, the design of laser welded blanks has evolved from very simple to rather complex layouts in order to comply with the continuously increasing challenges of weight reduction, engineering properties and cost [1]. Over the same period of time, companies active in this market and have developed various laser welding production concepts and related subtechnologies. Meanwhile, many of these have disappeared again since only those allowing to manufacture a superior product in terms of cost, quality and flexibility could survive in this highly competitive market. Principally two fundamental production concepts have been established. One concept uses a fixed laser head and moving the material along the head. The other concept moves the laser head over the material being in fixed position. Besides, hybrid concepts moving the head as well as the material in a coordinated way have also been realized for particular applications. Two key aspects control the optimization towards higher productivity and accordingly lower manufacturing cost: (i) material handling time and (ii) welding speed. A further important aspect towards reducing cost is to lower the part specific investment into tooling. For laser welding this concerns cutting dies as well as material handling and clamping devices. All these aspects have to be considered in combination when designing a welding machine for a particular application or market. Furthermore it is necessary to enhance process robustness to provide weld seams of consistently high quality. The operating window of stable processing conditions becomes smaller at higher welding speed. Therefore an innovative 
welding technology has been developed increasing process robustness without sacrificing welding speed or increasing heat input.

\section{Laser welded blank production concepts}

For laser welded blank production various manufacturing concepts are used in the industry $[1,2]$. These production concepts are the result of different production strategies and also of rapid parallel technology development by different players in the market. A production concept is basically characterized by way of achieving a relative displacement of laser beam and sheet material as well as by the manner of managing the material flow through the process. The driving forces behind any welding machine concepts are maximization of the utilization of the laser welding equipment, the optimization of production flexibility and the reduction of cost.

Fixed-optics laser welding systems are characterized by a stationary welding head while the sheet assembly to be welded is passing underneath (see Fig. 1). This technology allows producing straight weld seams (see Fig. 2). Moving optics systems represent the opposite approach where the sheets to be welded are at rest while the laser welding head is executing a linear or free form trajectory (see Fig. 3). In this way weld seams of arbitrary shape such as circular, curved or angular ones can be made. The technology also allows producing complex blank assemblies, as shown in Fig. 4. Considering the part spectrum in today's automotive market, the vast majority of blanks require straight weld seams connecting two or three individual sheets. For the production of single straight welded assemblies, machines equipped with fixed optics are clearly the method of choice. Each additional straight weld in a blank design requires a corresponding additional pass through the

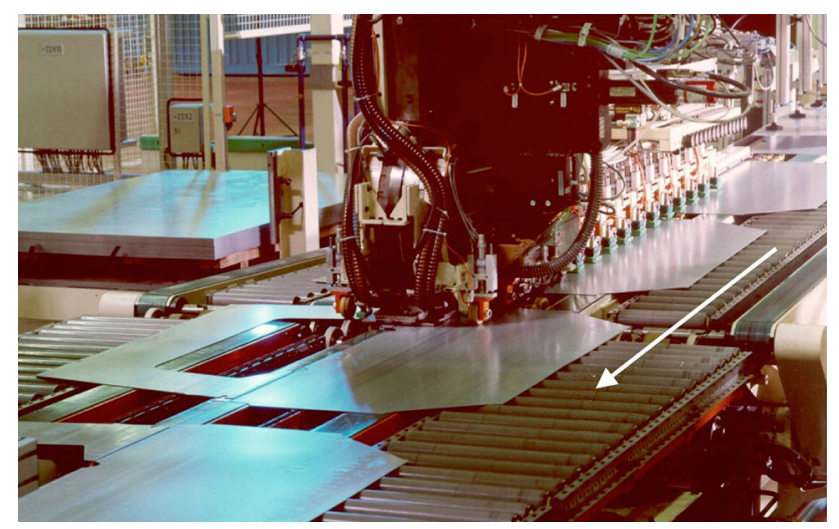

Fig. 1 Fixed-optics welding machine with continuous material feed $($ arrow $=$ feed direction $)$

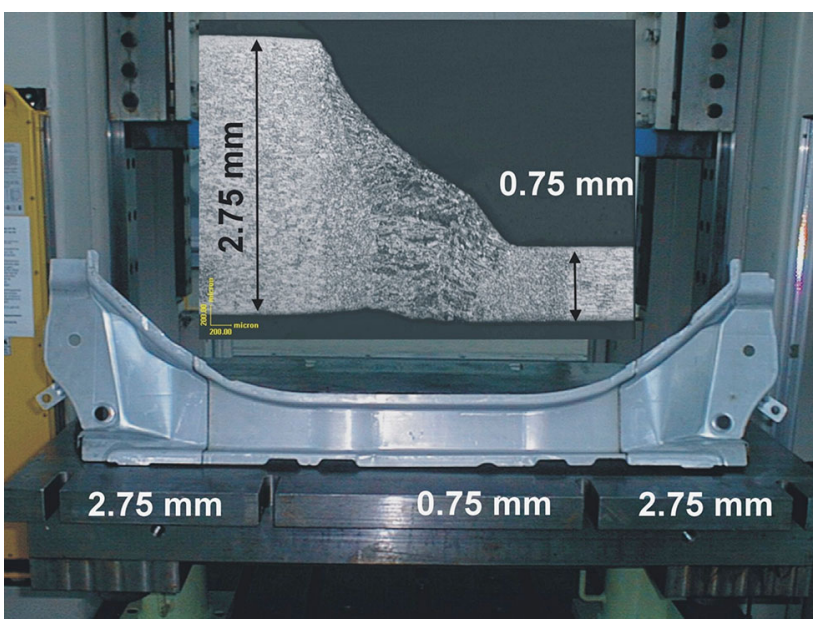

Fig. 2 Cross member with double linear weld seam and representative weld cross-section

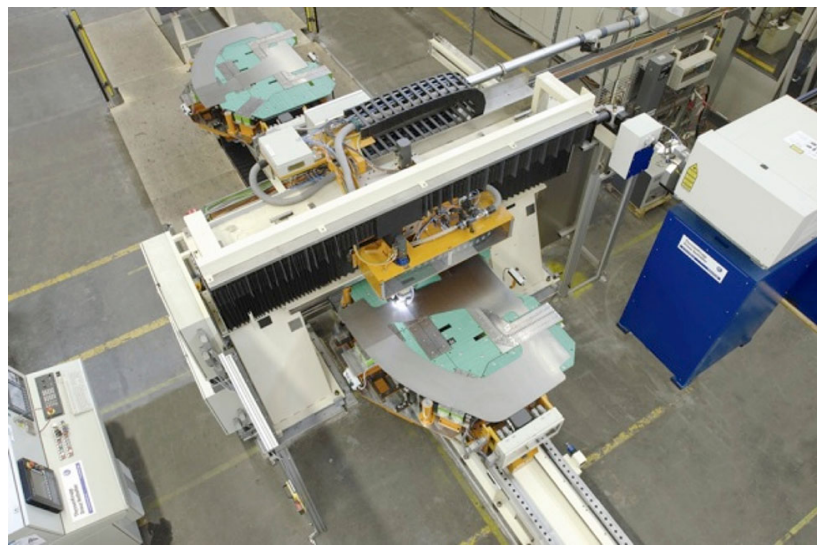

Fig. 3 Moving-optics welding machine for 2-D welding with discontinuous material feed

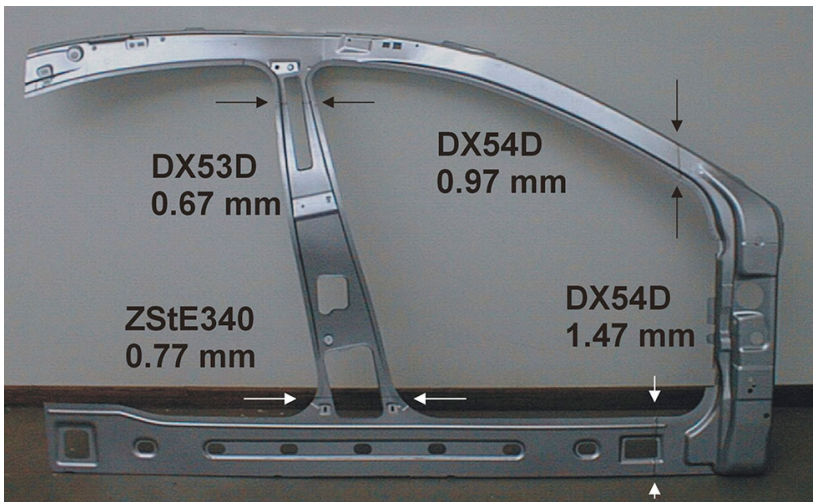

Fig. 4 Four-piece laser welded body side frame (weld seams indicated by arrows) 
machine since only one weld seam can be manufactured at the time. This results in extra handling and machine set-up effort whereas a moving optics system completes even complex multi-weld assemblies within one machine cycle. Therefore, detailed analysis of the manufacturing cycle time is required to decide which of the two machine concepts is to be preferred.

\subsection{Material feeding systems}

The challenge to the material-handling concept is to offer a new batch of non-welded sheets to the weld process as soon as the welding cycle of the previous is completed [3]. This scenario allows maximum utilization of the capital-intensive welding equipment and thus leads to reduction of the partspecific welding cost. Consequently, the ideal solution for operating a fixed-optics welding machine is continuous material flow through the welding machine. In this case the speed of conveying material into and out of the welding machine equals the actual welding speed. The distance between consecutive sheet batches is maintained to the possible minimum to keep the non-welding time as short as possible. In particular cases, accelerated material propulsion in between weld segments helps to reduce the non-welding time. Since welding cycles can be as short as a few seconds, appropriate buffer zones have to be foreseen at the beginning and the end of such a continuous feeding system. The continuous material feed system is based on the conveyor principle where the individual blanks are loaded and while moving onwards being positioned automatically [2]. Naturally this method does not allow static clamping of the sheet pair during welding. Dynamic clamping is achieved by inclined friction rolls pushing the two mating blanks against a locator guide and simultaneously moving them forward at welding speed. Just in front of the welding position the locator guide ends and the two blanks get in direct contact forming a butt configuration without a gap between the mating sheet edges.

Discontinuous feeding systems utilize a reversing shuttle, which is loaded with a batch of non-welded blanks that are positioned against reference pins and subsequently statically clamped. The shuttle is then moving the clamped blank set through the welding machine. Upon unloading the welded blanks at the end of the welding pass, the shuttle is returning empty to the loading position. The return and refill periods define an additional unavoidable non-welding time so that the overall productivity is inferior to that of a continuous feed system.

The continuous material feeding process offers the shortest possible handling time and thus represents as such the most efficient solution. Yet, in a scenario of various production jobs running on the same welding machine the total machine availability is determined by the changeover time from one production job to the next. Hence reduced changeover time is a much desired machine feature. The changeover time is directly related to the material handling system. The continuous feeding system does not involve any part specific tooling for material handling. The conveyor system taking care of the material flow adjusts itself to a new production job by a simple software command. Machines based on a discontinuous feeding system require a tooling change. Consequently a setup time typically in the order of 30-60 min is necessary prior to production. The impact of this setup time becomes more severe for the smaller production batches and hence more frequent job changes. Table 1 compares the continuous and discontinuous material feeding with a discontinuous feeding system based on a typical scenario for automotive blank welding on established production equipment. The process time per part provided by the continuous feeding system is approximately $30 \%$ shorter as compared to discontinuous feeding. Taking the changeover time and various batch sizes into account, the productivity of the continuous feeding line further increases [4].

\subsection{Weld edge preparation}

Since manufacturing of tailored blanks typically relies on an autogenous laser welding process, i.e., without using filler wire and the laser beam diameter is usually less than $0.5 \mathrm{~mm}$, the careful preparation of the blank welding edges is important. Squared edges with a high straightness are prerequisite to avoid local gaps between the blank edges causing undercut in the weld bead and thus insufficient mechanical properties of the weld. The generally accepted requirement for autogenous laser butt-welding is a butt gap of less than $0.1 \mathrm{~mm}$ along the entire butt interface. Figure 5 demonstrates the consequence of poor sheet edge conditioning resulting in increased butt gap and leading to undercut after laser welding.

Precision die blanking is the usual method for generating high quality blank edges suitable for laser butt welding (see Fig. 6). Such dies are costly and also require a high quality blanking press with precise guidance since the knife clearance is kept particularly small for obtaining squared cutting edge geometry. This consequently means that press forces are high. Laser cutting on the contrary can produce squared edges quite easily. Unfortunately, the productivity of laser cutting is too low for high-volume production of tailor-welded blanks. Thus laser cutting is only a suitable solution for prototyping and small-scale production.

For larger volumes, a low-cost alternative edge preparation solution has been developed. Shaped blanks are cut using conventional blanking dies that can be operated in standard blanking presses. A defined over-dimension on the welding edge (approx. $5 \mathrm{~mm}$ ) is foreseen in the die blanking process. The over-dimension is cut back by 
Table 1 Cycle time and batch production time for continuous and discontinuous material feeding (scenario: $1 \mathrm{~m}$ weld length per part, $50 \mathrm{~mm}$ part spacing sequence, $8 \mathrm{~m} / \mathrm{min}$ weld speed, 3 blanks per load cycle for discontinuous feeding system)

\begin{tabular}{|c|c|c|c|c|c|c|c|c|}
\hline \multirow[t]{2}{*}{ Feeding system } & \multicolumn{4}{|c|}{ Process time per welded part/s } & \multirow{2}{*}{$\begin{array}{l}\text { Job change- } \\
\text { over time/s }\end{array}$} & \multicolumn{3}{|c|}{ Production time per batch/min } \\
\hline & Welding & Travelling & Reloading & Total cycle & & 2,000 parts & 5,000 parts & 10,000 parts \\
\hline Continuous & 7.5 & 0.4 & 0.0 & 7.9 & 300 & 268 & 667 & 1,325 \\
\hline Discontinuous & 7.5 & 0.4 & 3.3 & 11.2 & 3,600 & 433 & 993 & 1,927 \\
\hline
\end{tabular}

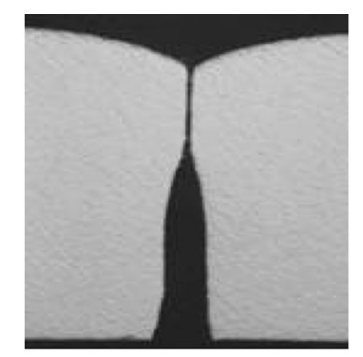

Poor edge condition

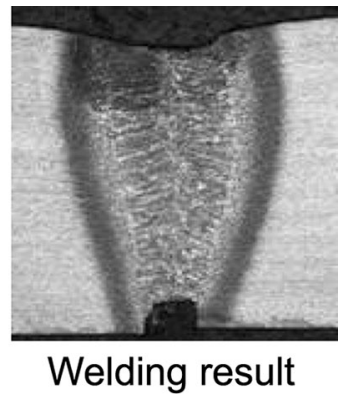

Fig. 5 Poor sheet edge conditioning resulting in increased residual butt gap and weld undercut
Good edge condition

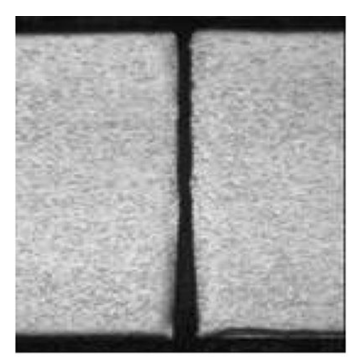

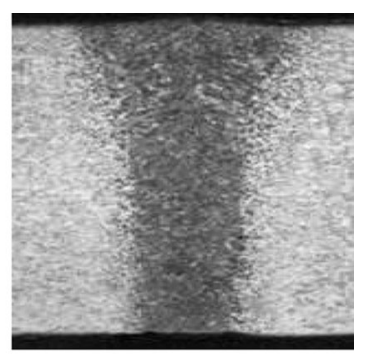

Welding result
Fig. 6 Optimum squared edge by precision die blanking or laser cutting resulting in flush weld surfaces

precision shears located in the entry section of the welding line. This set-up is shown in Fig. $7 \mathrm{~b}$ where two precision shears are positioned in the left and right of the continuous feeding conveyor. Robots pick the pre-blanked sheets, insert them into the shear and subsequently place them on the conveyor. This also excludes the risk of damaging the welding edge when transporting the blank stack from a stocking location to the welding line. Edge damage is the major cause of weld imperfections.

\subsection{Modular production concept for continuous welding}

The core module of a continuous welding line can be equipped with various handling facilities at the entry and exit of the line (see Fig. 7) [4]. The respective setup has influence on the investment cost and on productivity of the line. Local conditions in a specific market require an individual contemplation to find the optimum line configuration.

In the simplest configuration loading and unloading of the blanks is done by manual labor. Two workers place blanks on the conveyor in the entry section in this setup. At the exit of the line one or two workers, depending on the blank size, the welded blank is uploaded from the conveyor. Naturally such a mode of operation is favorable in countries where labor cost is low. Also the flexibility of changing between different orders is high since no hardware or tooling changes are required. Hence, this condition is very suitable for developing markets where batch sizes are small and/or product variety is high. In markets where labor cost is higher and/or larger order volumes have to be produced, manual labor can be replaced by mechanized material handling such as robots equipped with a suitable handling attachment or handling gantries in case of very high volume production. Other features like automatic blank dimpling to balance the stack height of the welded blanks and flip-over of welded blanks can be integrated downstream in the exit section of the line. Such a modular concept allows future upgrading from a core concept achieving higher productivity as the market demand is developing.

\section{Process considerations for laser welding}

Laser butt-welding makes use of the so-called keyhole welding process. In this process, the laser radiation is focused to a small spot of extremely high intensity. Material in the irradiated area is instantaneously evaporated and a vapor channel commonly known as keyhole is formed into the depth. The welding process relies then on a continuous displacement of the keyhole along the joining line. The material is melting around the keyhole and solidifying immediately after the keyhole has passed thus forming an autogenous weld. The heat-affected zone has thereby a high depth-to-width ratio rendering only a very small volume material with altered properties. The intensity of laser radiation in the focal plane as well as the 

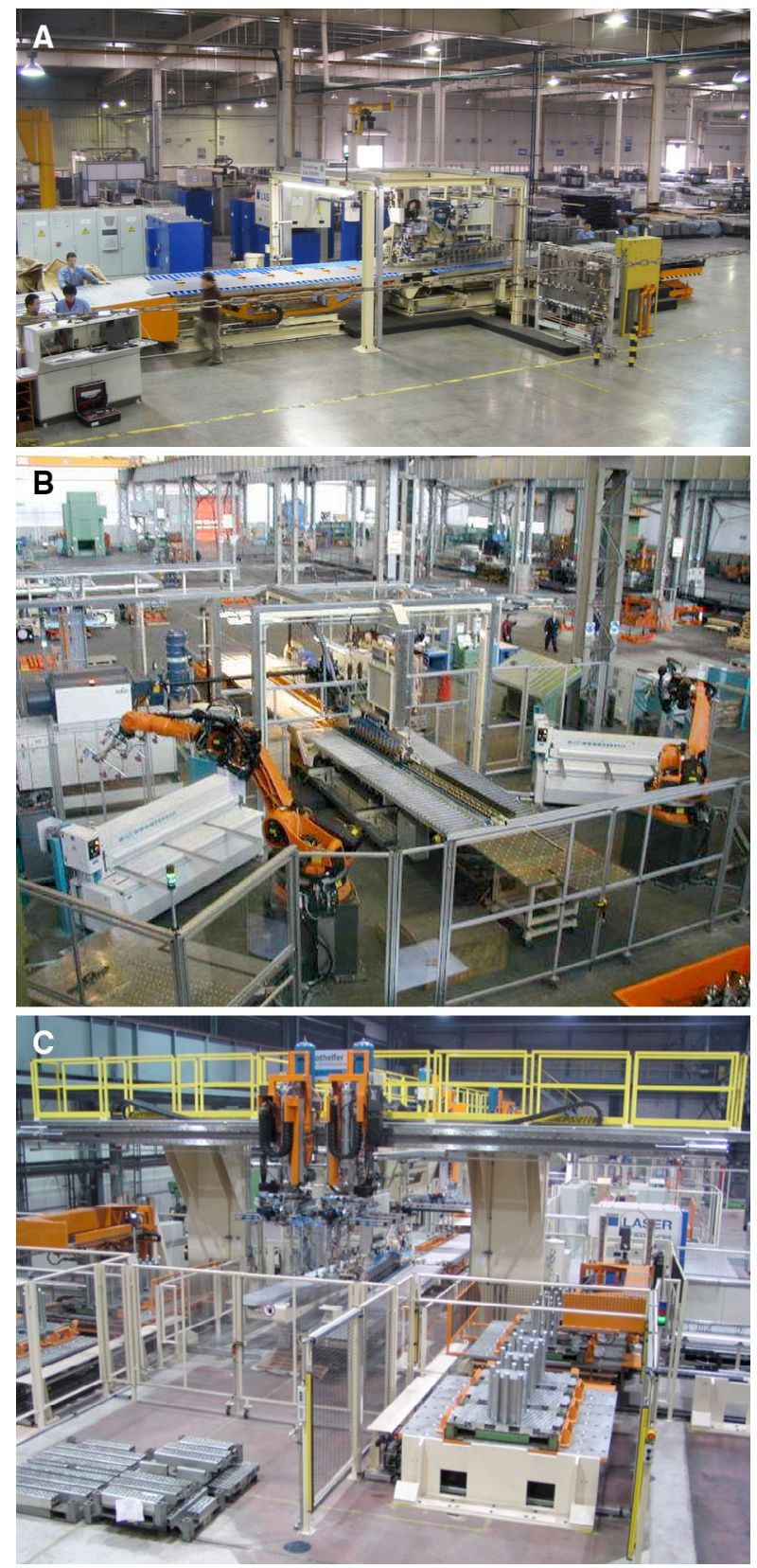

\section{Manual continuous welding line:}

- Manual loading of pre-material

- Automatic joining and centering of blanks

- Manual unloading of welded blanks

- Direct operating staff: 5 persons

- Relative investment: 100

Semi-automatic robot type continuous welding line:

- Manual or automatic loading of pre-material

- Optional in-line edge preparation by precision shears

- Automatic joining and centering of blanks

- Manual or automatic unloading of welded blanks

- Direct operating staff: 3 persons

- Relative investment: 140

Fully automatic gantry type continuous welding line:

- Automatic loading of pre-material

- Automatic joining and centering of blanks

- Automatic unloading of welded blanks

- Optional in-line dimpling and in-line turning

- Direct operating staff: 1 person

- Relative investment: 180

Fig. 7 Modular configuration options for laser welded blank welding system with continuous material feed

mean gage of the steel sheets to be welded determines the maximum achievable welding speed. Since the focal plane diameter is bound by a lower limit, being typically not less than $0.3 \mathrm{~mm}$, the average intensity and, thus, the welding speed at a given mean gage can only be increased by using higher laser power. In the early days of laser butt-welding, $\mathrm{CO}_{2}$ lasers were limited to $5 \mathrm{~kW}$ maximum power. Nowadays, $8 \mathrm{~kW} \mathrm{CO}$ lasers are most commonly used in the industry. In some cases, $12 \mathrm{~kW} \mathrm{CO}_{2}$ lasers have been used to further increase the welding speed. The advantage of increased laser power under standard monofocal butt-welding conditions manifests itself especially at heavier sheet gage (see Fig. 8). Generally, the welding speed appears to reach a maximum of around $10 \mathrm{~m} / \mathrm{min}$ under these operating conditions. At higher speed the welding process becomes less stable leading to frequent quality problems in the weld seam.

Figure 9 resumes the impact of laser power on the welding speed. The evolution of power from $2 \mathrm{~kW}$ to $8 \mathrm{~kW}$ initially could be directly converted into increased 
welding speed on a standard continuous welding system. There is also an upper limit to the intensity above which plasma shielding effectively blocks off the transmittance of $\mathrm{CO}_{2}$ laser radiation to the work piece. Therefore it is important to avoid intensity peaks within the focal plane especially when using laser of $8 \mathrm{~kW}$ or higher power. With increasing welding speed, however, material handling is becoming bottleneck so that the development of more efficient handling systems becomes necessary. Yet, a new welding technology is required to take full benefit

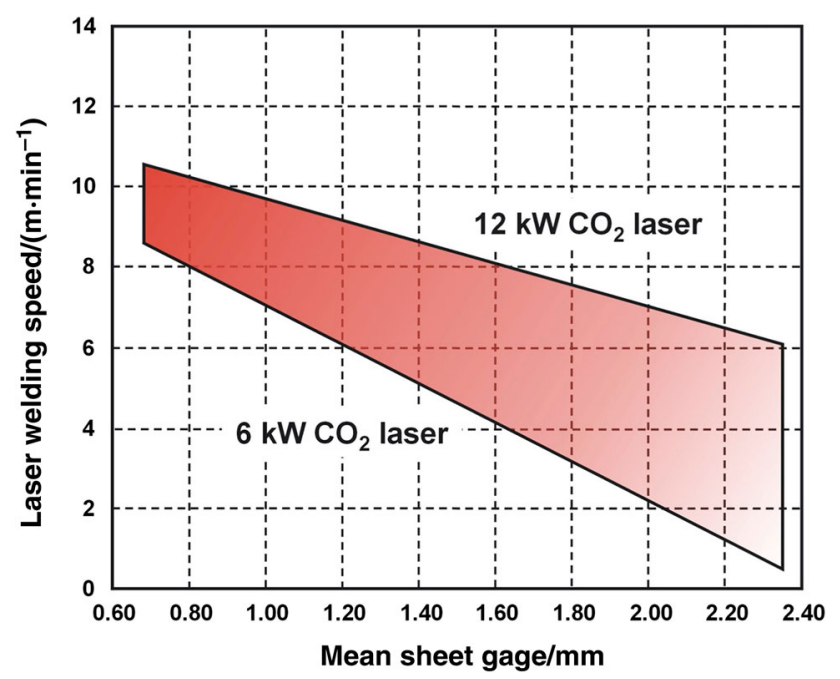

Fig. 8 Weld speed operating window defined by laser power and sheet gage combination of lasers in the $10 \mathrm{~kW}-12 \mathrm{~kW}$ range as will be discussed below.

Attention has to be paid also to the depth of focus, which controls the power concentration in the direction normal to the focus plane. Because of the limited thickness of automotive steel sheet, the focal depth should not be much larger than the sheet gage to obtain efficient coupling of the laser energy. This effect can be experimentally verified by defining the process efficiency as being the volume of fused metal per irradiated energy. The laser welding process becomes the most efficient when the depth of focus is nearly identical to the sheet gage (see Fig. 10) [1]. For a given beam quality and focusing optics the maximum possible process efficiency depends only on the sheet gages to be welded. Inferior process efficiency is typically caused by energy losses due to through gap transmission, surface reflection, or plasma shielding of the incident laser radiation.

\subsection{Methods enhancing process robustness}

Excessive gap along the butt joint due to insufficient weld edge preparation or thermal distortion causes transmission losses of laser radiation. The lost energy does not contribute to melting material and accordingly process efficiency is reduced. An established method increasing the robustness of the laser butt-welding process against residual joining gap is dual focus or twin spot welding [5]. This technique relies on splitting up the raw beam of one laser using a so-called beam splitter (see Fig. 11). The two

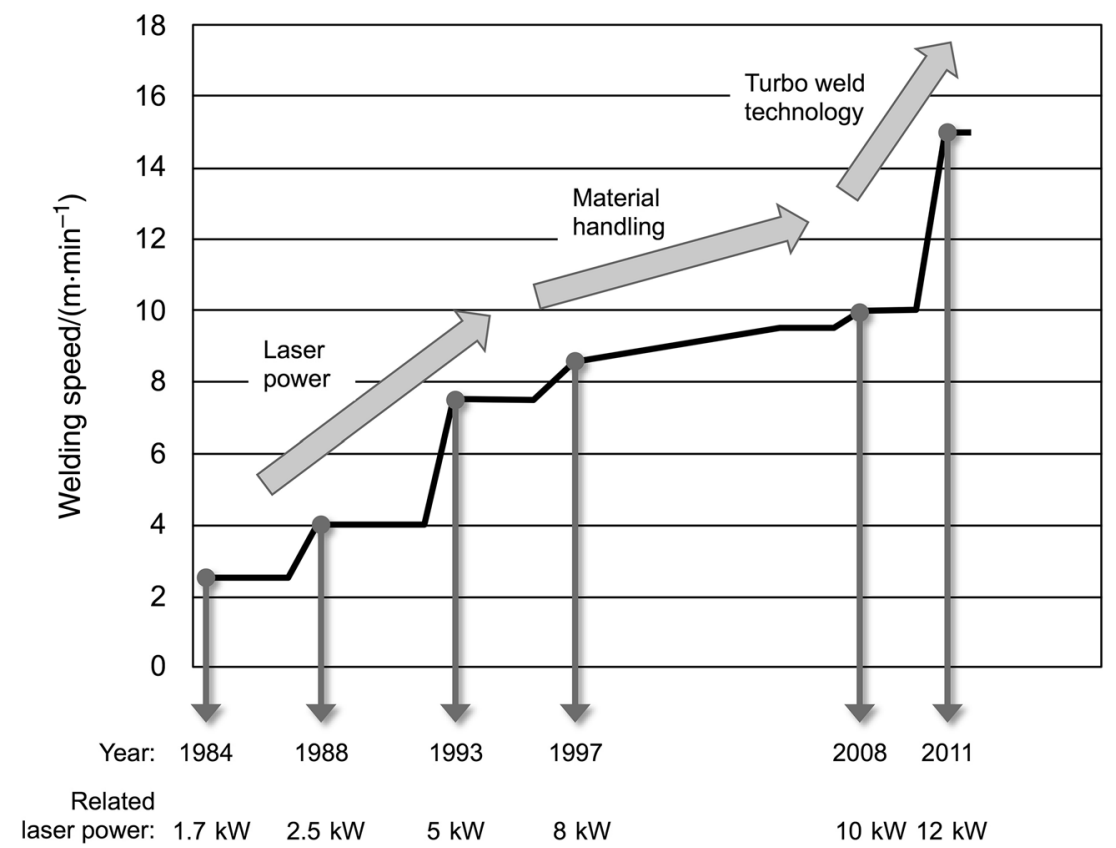

Fig. 9 Evolution of operational weld speed for a reference gage combination $(1.2 \mathrm{~mm}$ vs. $0.8 \mathrm{~mm})$ and technology impact 
partial beams are then focused on two spots with a defined small separation. Alternatively two separate laser spots can be delivered by two optical fibers when using two YAG lasers. The laser power can be adjusted asymmetrically to have higher power in one spot and lower power in the other. Practically this power distribution is often in the same ratio as the sheet thicknesses to be joined. The focal positions are left and right of the joining gap so that the transmission loss of laser radiation becomes negligible (see Fig. 11). Another possibility is to have the focus on the thicker gage in leading position and the one on the thinner

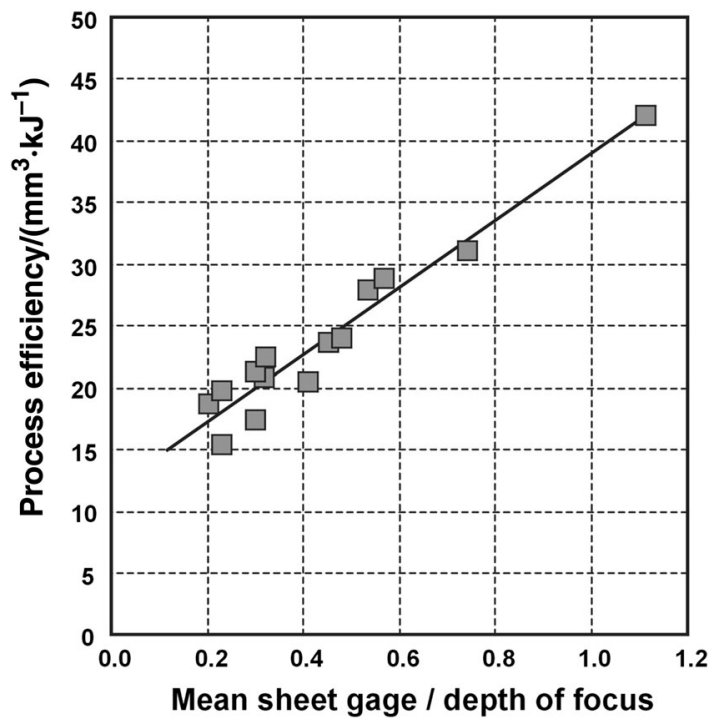

Fig. 10 Effect of focal length in relation to mean sheet gage on the efficiency of energy conversion in laser welding

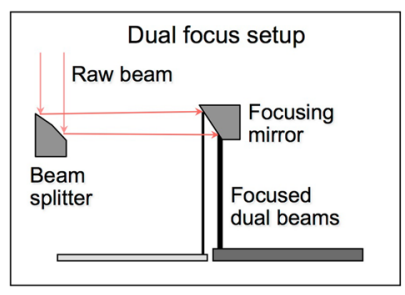

Single focus welding

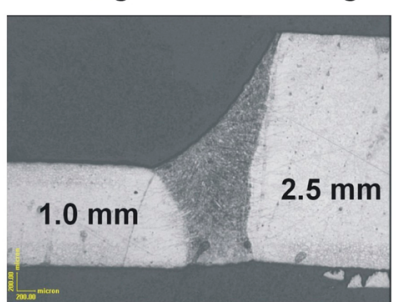

Fig. 11 Principle of dual focus welding and possible spot configuration on the blank surface and comparison of weld cross-section between single and dual focus welding gage in trailing position. In dual focus welding evidently more material is molten than in single focus welding. Accordingly the weld speed has to be lowered reducing productivity of the welding line and increasing the heat input. Consequently the heat affected zone is widened, which can result in inferior properties especially when welding ultra-high strength steel [6].

A frequently encountered problem reducing process robustness is gap opening during welding being the consequence of heat distortion. A very effective countermeasure has been developed specifically for the continuous welding system where strong static clamping is not possible. By localized cooling in the already welded hot zone, using for instance a water jet, a counter distortion is being induced that effectively closes the butt gap in the area just ahead of the weld process. This technique supports the action of the inclined friction rolls driving the blank pair forward and towards each other. Based on many years of production experience with this technology it can be concluded that the cooling device causes no negative effects on either weld or surface properties.

\subsection{High-speed welding technology}

Increasing the weld speed has a direct impact on the productivity of the welding line. According to Figs. 8 and 9 one can increase the welding speed by using a laser with increased power. However, at very high welding speed the keyhole process tends to become unstable. This phenomenon is noticed as a periodic undulation of the weld bead profile, also known as humping [7, 8]. The humping phenomenon manifests itself by the repeated formation of metal droplets on top and bottom surface as well as weld segments with severe undercut. Hybrid welding has often been propagated as a technology to avoid humping [9]. Here, the laser welding process is combined with arc welding. However, this setup requires two different power sources, complicates the construction of the welding head and naturally increases heat input significantly.

A more simple technology called "Turbo-Weld" has been recently developed to overcome the problems related to humping and to achieve a wider processing window. Turbo weld technology principally resumes the idea of twin spot technology explained before, however in a different configuration. The two laser beams are here focused from the top and down side relative to the sheet plane. Unlike in a conventional laser welding process the laser irradiating the topside does not aim for complete penetration but for increased speed. Consequently a weld with only partial penetration noticed as severe undercut is obtained (see Fig. 12). A second weld pass from the downside completes the weld by flattening out the existing undercut to a nearly flush surface (see Fig. 13). Thereby depth penetration is 
smaller so that the second weld pass requires less laser power. Furthermore, due to the presence of the topside weld no losses of laser radiation through gap openings are being encountered. Naturally also for turbo-weld technology the weld bead geometry is depending on the weld edge

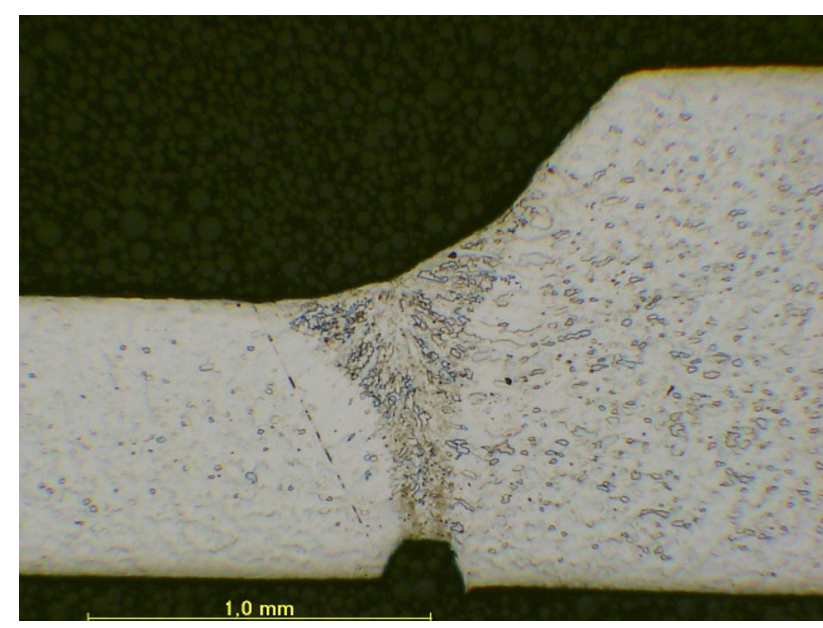

Fig. 12 Topside first pass weld $(8 \mathrm{~kW} \mathrm{CO}$ laser, $\mathrm{v}=18 \mathrm{~m} / \mathrm{min})$

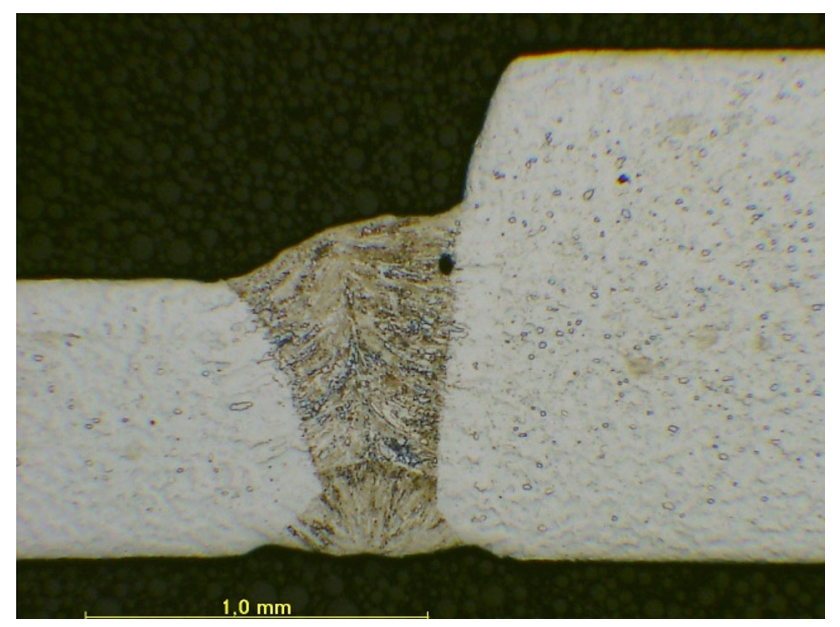

Fig. 13 Downside second pass weld (2 kW disc laser, $v=18 \mathrm{~m} /$ $\min )$

Table 2 Achievable maximum weld speed by Turbo-Weld technology using a $6 \mathrm{~kW}$ IPG fiber laser with power distribution $60 \%$ on topside / $40 \%$ on downside

\begin{tabular}{ll}
\hline Sheet gage combination & $\begin{array}{l}\text { Achievable max. welding } \\
\text { speed with Turbo-Weld technology }\end{array}$ \\
\hline $1.25 \mathrm{~mm}$ vs. $2.00 \mathrm{~mm}$ & $18 \mathrm{~m} / \mathrm{min}$ \\
$0.94 \mathrm{~mm}$ vs. $1.25 \mathrm{~mm}$ & $24 \mathrm{~m} / \mathrm{min}$ \\
$0.60 \mathrm{~mm}$ vs. $0.94 \mathrm{~mm}$ & $28 \mathrm{~m} / \mathrm{min}$ \\
\hline
\end{tabular}

condition. If this condition is met, i.e., squared-edge geometry with high straightness exceptionally high welding speeds can be obtained, as reported in Table 2. In a direct comparison under industrial conditions (see Fig. 14) using the $1.25 \mathrm{~mm}$ vs. $2.00 \mathrm{~mm}$ sheet gage combination, conventional single focus welding resulted in a maximum welding speed of $8.5 \mathrm{~m} / \mathrm{min}$ whereas twin-spot Turbo-Weld technology achieved a speed of $14 \mathrm{~m} / \mathrm{min}$. With optimum weld edge preparation a weld speed of $18 \mathrm{~m} / \mathrm{min}$ is feasible by Turbo-Weld technology.

On-going refinement of the Turbo-Weld process concentrates on optimizing the overlap of the two weld beads in thickness direction as well as the alignment of the two focal points transverse to the welding direction. A minimum overlap of $20 \%$ (see Fig. 15) is recommended for obtaining sound weld quality, which in essence determines the weld speed or the laser power to be used. The topside focal point is often laterally positioned towards the thicker of the two sheets to be welded. In that way additional material can be molten to fill the small residual gap existing between the sheet edges. The downside beam is then focused on the weld center. Thus a defined offset

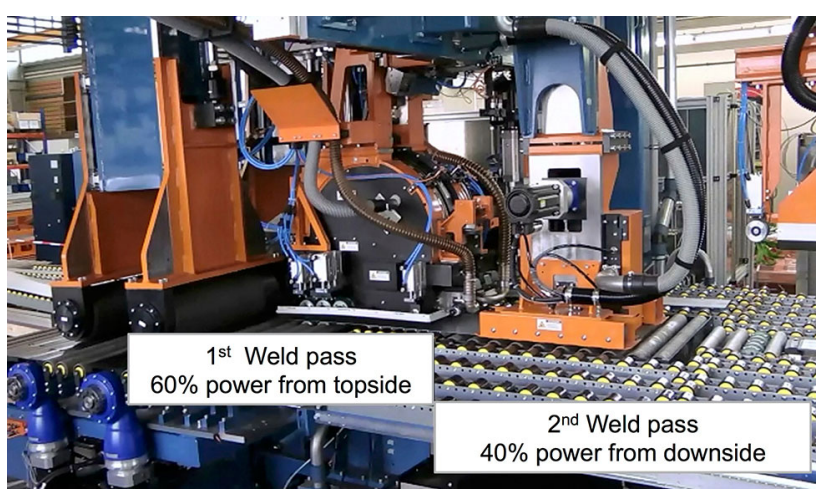

Fig. 14 Industrial Turbo-Weld set-up using a $6 \mathrm{~kW}$ IPG fiber laser with asymmetric power sharing

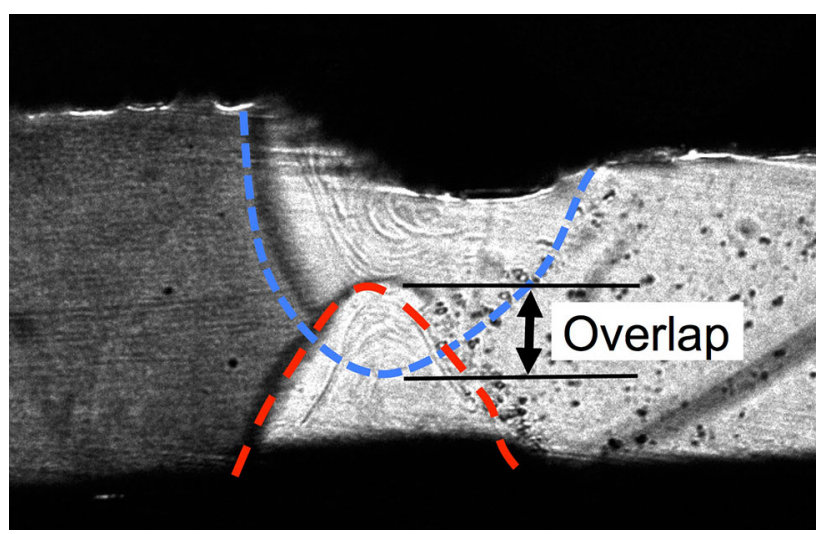

Fig. 15 Turbo-Weld cross-section for a sheet gage combination of $0.94 \mathrm{~mm}$ vs. $1.25 \mathrm{~mm}$ welded at $20 \mathrm{~m} / \mathrm{min}$ 
between the two focal points is to be adjusted and maintained. Optical seam-tracking devices can be used to steer the exact lateral positioning of the two beam foci.

\section{Tailor welded coil technology}

According to Fig. 9 effective welding speed and thus line productivity has been achieved by technology jumps as well as by detail improvements. With increasing available laser power speed the material handling became capacity bottleneck. The continuous welding line with a high degree of automation has so far been the best technology to exploit the weld speed possible with conventional single focus laser welding. The very high weld speed of Turbo-Weld technology however can make the material handling of discrete blanks again a limiting factor.

Tailor welded coil technology has been developed as a new process allowing even faster material feed to the laser welding line [10]. In this process two or more coils are joined along the coil edge, as schematically depicted in Fig. 16. Principally, the speed of material feeding is controlled by the coiling device and constitutes no limit with respect to welding speeds achieved with Turbo-Weld technology. Furthermore, non-welding time is completely avoided compared to welding of individual blanks. On the machine exit side two scenarios are possible. Either the welded material is coiled up again or it is processed into individual blanks using an integrated shear or a blanking press. Principally the spectrum of parts that can be generated based on tailored-coil welding is more limited than that using a traditional tailored blank welding line.
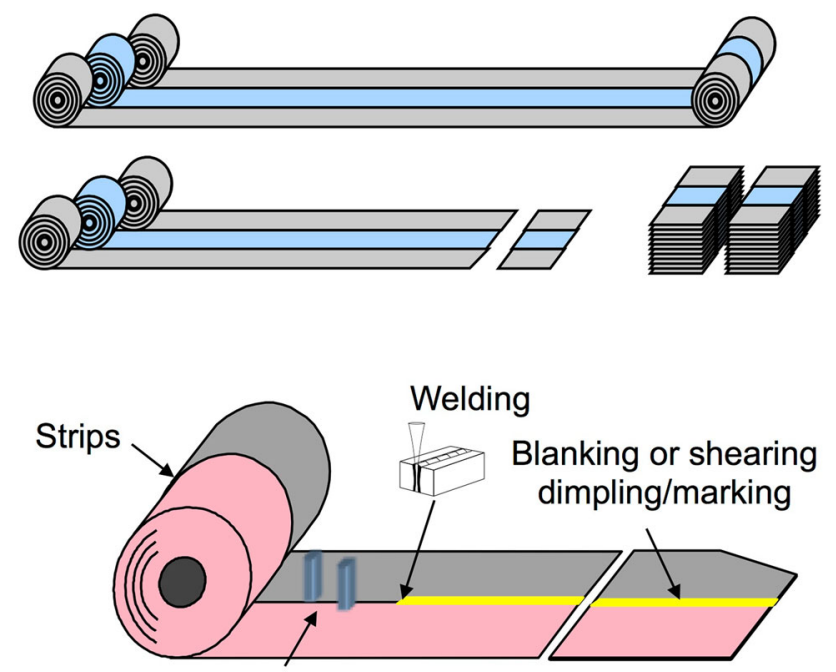

In-line edge preparation

Fig. 16 Concept of tailor welded coil technology and product varieties
The core unit of the tailor welded coil system (see Fig. 17) incorporates a number of auxiliary technologies besides the actual Turbo-Weld laser units. Upstream of the welding station in-line edge preparation reconditions the inferior geometry of a natural or slit coil edge to squarededge geometry as defined by Fig. 6. Nevertheless the formation of a weld defect can never be completely ruled out. Therefore a weld quality monitoring station is installed downstream the welding units. When the welded coil is immediately processed into individual blanks, those parts containing a defect can be automatically sorted out. In case the welded coil is wound up for later processing, the defect containing section can be indicated by a marking hole allowing removing it during subsequent offline processing. A further device embosses dimples on the thinner gage side at regular positions to balance the gage difference and to allow stable coil winding or stacking. An example for a produced tailor welded coil where four slit coils have been joined together is given in Fig. 18. Besides efficient production of standard tailored blanks this innovative product offers a range of completely new applications. For instance tailored profiles can be produced by roll profiling a tailor welded coil allowing optimization of weight and stiffness. Other examples are the production of weight-optimized wheel rims or exhaust line components.

\section{Conclusions}

Laser welding principally is an efficient manufacturing technology for high quality products made of sheet metal. However it was demonstrated that significant efficiency

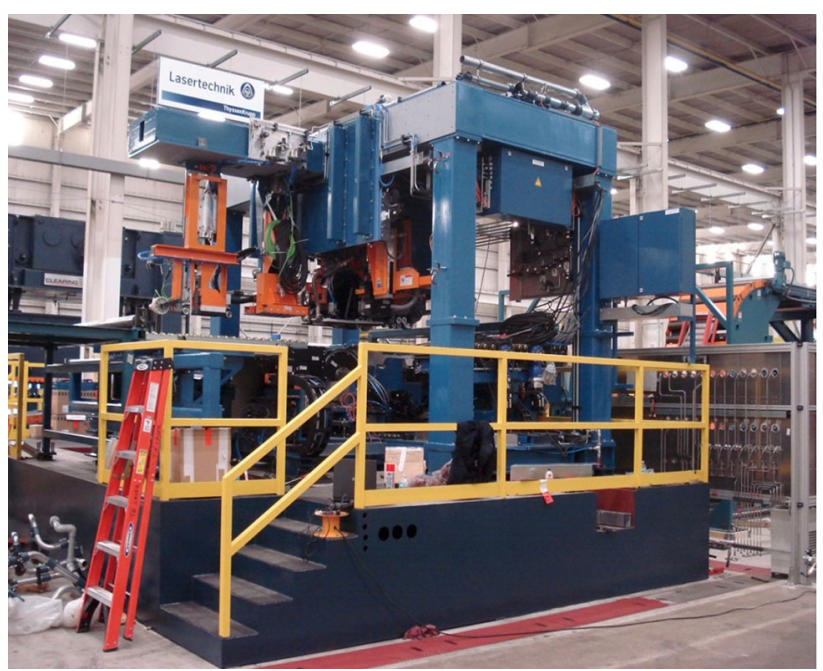

Fig. 17 Core unit with laser weld cell of an industrial tailor welded coil production line 

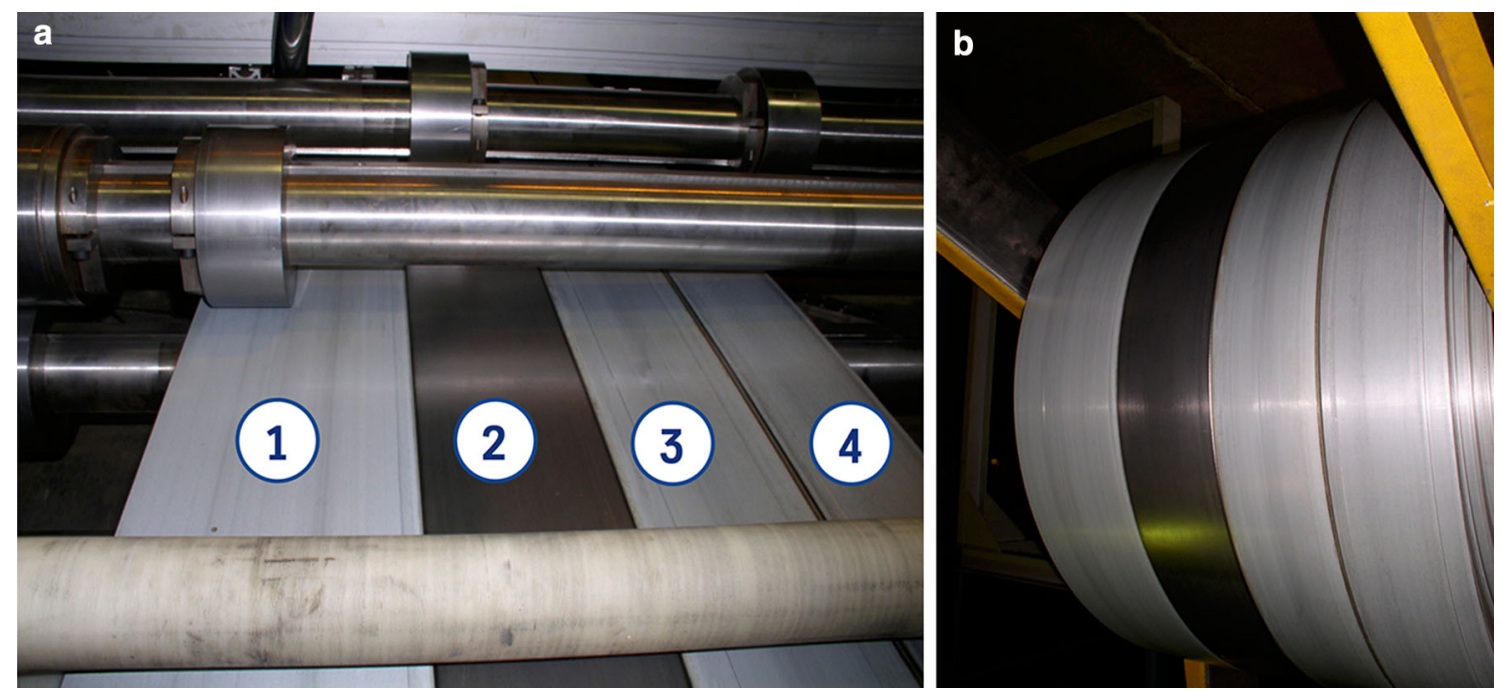

Fig. 18 Example of advanced tailor welded coil consisting of 4 slit coils (a machine exit section, $\mathbf{b}$ coiling of the welded strip). Strip dimensions (1) $t=0.75 \mathrm{~mm}, w=180 \mathrm{~mm}$; (2) $t=2.0 \mathrm{~mm}, w=125 \mathrm{~mm}$; (3) $t=0.8 \mathrm{~mm}, w=125 \mathrm{~mm}$; (4) $t=2.0 \mathrm{~mm}, w=100 \mathrm{~mm}$

gains were possible by optimizing material handling and auxiliary technologies in an integrated way. Continuous material feed is the most effective technology for enabling short cycle times. This technology has been continuously refined and applied for mass production since two decades. Recently direct feeding of coils to the laser welding process has allowed reaching the upper limit of feeding efficiency. Therefore the emphasis has shifted on further increasing the welding speed. "Turbo Weld" technology executing two overlapping partial penetration welds from either side of the sheet enables a drastically increased welding speed at simultaneously high process robustness. Tailor Welded Coils offer a high potential of further optimizing efficiency in subsequent manufacturing processes and reducing product cost.

\section{References}

1. Mohrbacher H (2001) A critical review of laser welding technology for mass production of tailored blanks. In: Proceedings of the international conference sheet metal 2001, Leuven Belgium, p 305
2. Schneider CH, Prange W (1995) Tailored blanks - a material for new ways of design. Thyssen Technische Berichte, Nr. 1, pp 97-106

3. Spoettl M (2008) High performance laser welding systems for the production of innovative laser welded automotive components. In: Proceedings of the Taiwan international steel technologies symposium, Kaoshiung, Taiwan, China, paper D24

4. Spoettl M (2009) A review of laser welding technology for mass production of tailored blanks. In: Proceedings of the 1st international symposium on automobile steel, Beijing, China, p 382

5. Xie J (2002) Dual beam laser welding. Welding J 81:223-230

6. Mohrbacher H (2005) Laser welding of modern automotive high strength steels. In: Proceedings of the 5th international conference on HSLA steels, Vol 40, p 582

7. Wei PS, Chuang KC, Ku JS et al (2012) Mechanisms of spiking and humping in keyhole welding. IEEE Trans Comp Packag Manuf Technol 2(3):383-394

8. Amara EH, Fabbro R (2010) Modeling of humps formation during deep-penetration laser welding. Appl Phys A 101:111

9. Choi HW, Farson DF, Cho MH (2006) Using a hybrid laser plus GMAW process for controlling the bead humping defect. Welding J 85(8):174-179

10. Spoettl M, Mohrbacher H (2013) Innovative laser-based manufacturing concepts for automotive steel processing. In: Proceedings of the 2nd international symposium on automobile steel, Anshan, China, p 173 